professional discussion. It is difficult to see how a PRO would be able to alter this state of affairs. If, however, the College has aims or objects which it wishes to achieve, Dr David Clark suggests that these might be defined and advice on procedure be sought from Public Relations Consultants. Such an approach is likely to cost a great deal of money.

Dr Haslam and his group have put a lot of hard work into seeking solutions to these problems, but the result of their labours adds little to the Memorandum produced in 1972 by the College's Public Policy Committee, or to Dr Clark's Memorandum to the PPC in 1974. The dilemmas remain unresolved.

\title{
GORRESPONDENGE
}

\section{THE QUALITIES OF A GOOD PSYGHIATRIST}

DeAr Sir,

Re Sir Denis Hill's lecture(1): the book(2) he quoted was written in the belief that if you cannot beat them or join them it is best to co-operate with them. If doctors always insist on being the leaders in a group, can they expect other professions to accept this and give full co-operation?(3)

Alex Baker

Donal F. EarLy

Alpina,

Theescombe Lane,

Amberley, Gloucestershire.

\section{References}

Hirl, Sir Denis (1978) The qualities of a good psychiatrist. British Fournal of Psychiatry, 133, 97-104.

Baker, A. A. (Ed.) Comprehensive Psychiatric Care. Blackwell, 1976 .

The consultant, one who consults (an oracle). Bulletin of the Royal College of Psychiatrists, June 1978, pp 1 10-1.

\section{NATIONAL MARRIAGE GUIDANGE GOUNGIL}

\section{Marital Sexual Dysfunction Project}

The DHSS has notified us of a project which is being funded by the Department to train marriage guidance counsellors in the treatment of certain sexual problems. In 1974 it was agreed to fund an experimental study to examine:

i. The feasibility of providing a training programme for marriage guidance counsellors to enable them to treat sexual dysfunction using non-counselling special treatment methods without undermining their existing skill in counselling;

ii. the feasibility of staffing a co-therapy service without having a highly professionally qualified person as one of the co-therapists, and (as a further development) the feasibility of staffing the service with single 'non professional' therapists.

Following an evaluation of the Study, NMGG has been given financial support for a further three years to develop and extend this training. The main aims of the present project are:
The continuation of apprenticeship training. In the first year of the NMGC's 'apprenticeship training' the trainer acted as senior co-therapist and the trainee as junior co-therapist in treatments based at Herbert Gray College in Rugby. In the next year, the erstwhile trainee acted as trainer and senior co-therapist, with a new trainee, at the new trainer's own MGC. These cycles are planned to repeat themselves annually, so spreading training gradually outwards from Rugby.

At this stage in the project the number of people who can be offered treatment at each centre is quite small, and outside the Midlands treatment is available at only a few MGCs (see list following). However, treatment will start in several more in the second year of the project.

The NMGC recognize the importance of developing and maintaining links with doctors and NHS services providing advice and treatment for sexual problems. 
West region

Bristol Marriage and Family Guidance Council, 75 Whiteladies Road, Bristol BS8 2NT (Tel. Bristol $3^{12316)}$

Bath and District Marriage Guidance Council, Gascoyne House, Upper Borough Walls, Bath BAI IRN (Tel. Bath 65593)

Southampton and District Marriage Guidance Council, 32 West Park Road, Southampton SOI 2 AS (Tel. Southampton 29761)

Oxfordshire Marriage Guidance Council, 33 Iffley Road, Oxford OX 4 IEA (Tel. Oxford 42960)

\section{East region}

London Marriage Guidance Council, 76a New Cavendish Street, Harley Street WIM 7LB (Tel. or-580 ro87)

|North West region

Manchester Marriage Guidance Council, Gaddum Centre, 274 Deansgate, Manchester M3 ${ }_{4} \mathrm{HB}$ (Tel. $061-8349163 / 4834$ )

Preston and District Marriage Guidance Council, 160 Garstang Road, Fulwood, Preston (Tel. Preston 717597)

Northern Ireland Marriage Guidance Council, 76 Dublin Road, Belfast BT2 7 HP (Tel. Belfast 23454)

North East region

Rotherham Marriage Guidance Council, 8 Percy Street, Rotherham (Tel. Rotherham 77644)

South Humberside Marriage Guidance Council, 4 Dudley Street, Grimsby (Tel. Grimsby 54392)

South region

Croydon and District Marriage Guidance Council,
- 9 Ramsey Court, Church Street, Croydon CRo I9RF (Tel. or-680 1944)

\section{Midland region}

Coventry and District Marriage Guidance Council, Gorton House, 11 Priory Row, Coventry CVI 5 EX (Tel. Coventry 25863)

Northamptonshire Marriage Guidance Council, 24 Hazelwood Road, Northampton NNI ILN (Tel. Northampton 34400)

Nottinghamshire Marriage Guidance Council, 84 Mansfield Road, Nottingham NGI $3 \mathrm{HD}$ (Tel. Nottingham $578{ }_{3} 6$ )

Leicester and Leicestershire Marriage Guidance Council, 94 London Road, Leicester LE2 oQS (Tel. Leicester 54301 I)

Birmingham Marriage Guidance Council, 71 Broad Street, Birmingham B 15 IAQ (Tel. 02 1-643 1638)

* Lichfield Marriage Guidance Council, Frogmorton House, Frog Lane, Lichfield, Staffs (Lichfield 52760)

* South Warwickshire Marriage Guidance Council, 33 Regent Grove, Leamington Spa (Tel. Leamington Spa 24899)

Herefordshire Marriage Guidance Council, 4a St. Owen Street, Hereford (Tel. Hereford 6023)

Burton-upon-Trent Marriage Guidance Council, 27 Union Street, Burton-upon-Trent DEI4 IAG (Tel. Burtonupon-Trent 61697)

* Rugby Marriage Guidance Council, 35a Regent Street, Rugby (Tel. Rugby 65675)

* Kettering Marriage Guidance Council, (outpost) (Tel. Northampton 34400)

*Denotes single therapy (not co-therapy).

\section{FORTHGOMING EVENTS}

\section{Institute of Family Therapy}

Supervision Workshops in Family Therapy, intended for those who have attended an introductory course and have had some clinical experience in family therapy, will be held on Wednesday mornings for 20 sessions, beginning on 17 January. Further details and application forms from Ms Alex Lowe, Institute of Family Therapy, 5 Tavistock Place, London, W.C.r.

\section{Henderson Hospital}

A ten-session day release course in Group Work will be held at the Henderson Hospital on Thursdays, January-March 1979. For particulars and application form write to the Group Work Course Secretary, Henderson Hospital, 2 Homeland Drive, Brighton Road, Sutton, Surrey SM2 5 LT.

\section{Institute of Child Health}

A one-week course in Child Psychiatry, organized by the Institute of Child Health in conjunction with members of the staff of the Hospital for Sick Children, Great Ormond Street, will be held from 26 February-2 March. Application forms from: The Sub-Dean, Institute of Child Health, 30 Guildford Street, London WGrN IEH.

\section{Institute of Family Psychiatry}

A two-day course in Family Psychiatry intended for psychiatrists will be held on 20 and 21 June 1979, at the Institute of Family Psychiatry, Ipswich. Programme and application form from the Institute, The Ipswich Hospital, 23 Henley Road, Ipswich IPI 3 TF. 